\title{
Bank vole alarm pheromone chemistry and effects in the field
}

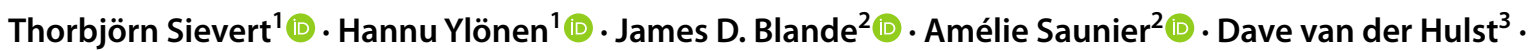 \\ Olga Ylönen ${ }^{1} \cdot$ Marko Haapakoski $^{1}{ }^{10}$
}

Received: 26 May 2021 / Accepted: 19 June 2021 / Published online: 25 June 2021

(c) The Author(s) 2021

\begin{abstract}
Chemical communication plays an important role in mammalian life history decisions. Animals send and receive information based on body odour secretions. Odour cues provide important social information on identity, kinship, sex, group membership or genetic quality. Recent findings show, that rodents alarm their conspecifics with danger-dependent body odours after encountering a predator. In this study, we aim to identify the chemistry of alarm pheromones (AP) in the bank vole, a common boreal rodent. Furthermore, the vole foraging efficiency under perceived fear was measured in a set of field experiments in large outdoor enclosures. During the analysis of bank vole odour by gas chromatography-mass spectrometry, we identified that 1-octanol, 2-octanone, and one unknown compound as the most likely candidates to function as alarm signals. These compounds were independent of the vole's sex. In a field experiment, voles were foraging less, i.e. they were more afraid in the AP odour foraging trays during the first day, as the odour was fresh, than in the second day. This verified the short lasting effect of volatile APs. Our results clarified the chemistry of alarming body odour compounds in mammals, and enhanced our understanding of the ecological role of AP and chemical communication in mammals.
\end{abstract}

Keywords Bank vole $\cdot$ Alarm pheromone $\cdot$ Mammalian body odour $\cdot$ Predator-prey interactions

\section{Introduction}

Predator-prey interactions are among the strongest drivers of evolution (Abrams 1986, 2000; Yoshida et al. 2003). In the context of an evolutionary arms race, early recognition of predation risk by prey is essential for prey survival and fitness. Cues of increased predation risk range from very reliable cues like sighting of a predator or its direct attack (Blumstein et al. 2000; Van der Veen 2002), to more general and less accurate ones like signs or markings of predator

Communicated by Janne Sundell.

Thorbjörn Sievert

thorbjoern.sievert@gmx.net

1 Department of Biological and Environmental Science, Konnevesi Research Station, University of Jyväskylä, P.O. Box 35, 40014 Jyväskylä, Finland

2 Department of Environmental and Biological Sciences, University of Eastern Finland, P.O. Box 1627, 70211 Kuopio, Finland

3 Environmental Sciences Department, Resource Ecology Group, Wageningen University, 6700 AA Wageningen, Netherlands revealing its presence or visit in vicinity. These signs include odorous faeces or other scent cues (Kats and Dill 1998). However, these cues do not necessarily have to originate from the predator, as the other option for information on predator are cues carried by conspecific prey, which often can even be more reliable than a mere predator odour (Blumstein et al. 2000; Randler 2006; MacLean and Bonter 2013).

After perceiving increased predation risk, multiple mechanisms and adaptations by prey animals are possible, from simple immediate behavioural responses to long-term physiological or even intergenerational adaptations (Abrams 2000). Anti-predatory behaviours employed in prey range from simple avoidance of high-risk areas (Ferrero et al. 2011; Clinchy et al. 2013; Pérez-Gómez et al. 2015) and freezing to decrease detectability (Wallace and Rosen 2000; Sundell and Ylönen 2004), over changes in vigilance and foraging (Brown 1999; Ylönen and Brown 2007; Embar et al. 2011), to drastic changes in the reproductive behaviours (Ylönen and Ronkainen 1994; Sih 1994; Mappes and Ylönen 1997; Mönkkönen et al. 2009; Haapakoski et al. 2012, 2018; Sievert et al. 2019).

If a prey individual survives a direct encounter with a predator, it may increase its own and its conspecifics' 
survival and later fitness by signalling predator presence intraspecifically. Several means of intra-species predator communication have been studied in animals, from simple group flight behaviours in birds (Adamo and McKee 2017) to elaborate vocal signalling in primates (Ouattara et al. 2009) and Mungotinae (Townsend et al. 2012; Collier et al. 2017). Another pathway of communication is fear or risk signalling body secretions or alarm pheromones (AP). These are widespread in invertebrates, such as sea anemones (Howe and Sheikh 1975), ants (Crewe and Blum 1970b), aphids (Bowers et al. 1972; Beale et al. 2006) or mites (Kuwahara et al. 1989), but also occur in vertebrates such as fish (von Frisch 1938; Wisenden et al. 2004; Mathis and Smith 2008). In the last two decades, a growing number of studies were able to show the presence of AP also in mammals, such as Wistar rats (Kiyokawa et al. 2004; Gutiérrez-García et al. 2007; Inagaki et al. 2009, 2014), C57BL/6J and OMP-GFP mice (Brechbühl et al. 2013), Cabrera voles (Microtus cabrerae) (Gomes et al. 2013), and even in domestic cattle (Aubrac breed) (Boissy et al. 1998) and pigs (Vieuille-Thomas and Signoret 1992). Several of the aforementioned species live in social groups, so the secretion of AP serves to warn the group, family or colony.

While the structure of AP remains unresolved for most mammalian species, it has been identified in, for example, aphids (Bowers et al. 1972), sea anemones (Howe and Sheikh 1975), and several insects (Heath and Landolt 1988; Kuwahara et al. 1989). Work on lab rodents has allowed for the analyses of alarm pheromones in Wistar rats (Inagaki et al. 2014), and C57BL/6J and OMP-GFP mice (Brechbühl et al. 2013).

In this study, we use the term "pheromone" to indicate semiochemical communication between individuals of the same species, as opposed to allelochemicals which facilitate communication between two different species (Dicke and Sabelis 1988; Sbarbati and Osculati 2006). We acknowledge that the secretion discussed in this study may have allelochemical properties, but there is no evidence of this in mammals yet.

Semiochemical communication is of great importance in mammals (Müller-Schwarze 1983; Dehnhard 2011; Apps 2013). It is used to convey a wide array of information, among others reproductive status (Pankevich et al. 2004), immunocompetence (Spehr et al. 2006), stress (Gomes et al. 2013) and effects in the mate choice (Roberts et al. 2010). This does not only occur in small mammalian species (Gomes et al. 2013; Inagaki et al. 2014), but also in large ones, e.g. muskox (Ovibos moschatus) and giant pandas (Ailuropoda melanoleuca) (Flood 1992; Wilson et al. 2018), as well as in primates (Evans 2006; Setchell et al. 2011) and humans (Stern and McClintock 1998; Thornhill and Gangestad 1999).
Previous behavioural studies have already shown alarm pheromone effects on reproductive behaviour in bank voles, specifically differences in the number of offspring (Haapakoski et al. 2018), the amount of parturitions (Sievert et al. 2019), and several transgenerational effects (Sievert et al. 2020). While the effects of an alarm pheromone exposure have been studied, the actual nature remains unclear. This study combines two goals with two different experimental designs: first to identify the chemicals involved in semiochemically signalling alarm in bank voles and second, to verify the effects of these alarm compounds on behavioural decisions of bank voles in the field compared to direct predator presence cue in form of predator odour. In the laboratory study, we sampled vole-derived volatile organic compounds (VOC) after exposing our experimental bank voles to three different stimuli: a live predator $(\mathrm{P})$, handling by a researcher $(\mathrm{H})$, and no stimulus $(\mathrm{C})$. The VOCs were collected by dynamic headspace sampling and analysed by gas chromatography-mass spectrometry (GC-MS). In the field study, we investigated how the presence of alarm pheromone, compared to predator odour and a control, shapes the foraging effort of voles over time. For the field part of the experiment, we predicted alarm pheromones to carry important but sensitive information, and expected to see only short-time effect of volatile APs compared to more longlasting risk cue of predator odours.

\section{Materials and methods}

\section{Study animals and site}

The bank vole (Myodes glareolus) is one of the most common small rodents living in a variety of northern temperate and boreal European forest habitats west of the Urals (Stenseth 1985). The species is granivorous-omnivorous, with their diet consisting mainly of seeds and buds, but also of other plant materials or invertebrates (Hansson 1979; Eccard and Ylönen 2006). In Central Finland, where this work was conducted, bank voles breed three to five times per season, which lasts from May until September (Mappes et al. 1995; Koivula et al. 2003).

Bank voles are preyed upon by a diverse predator assemblage, including least weasels (Mustela nivalis) and stoats (Mustela erminea) (Ylönen 1989; Meri et al. 2008). The least weasel is an especially effective hunter of voles due to their size and excellent hunting skills, least weasels are likely able to kill bank voles whenever the two species come into direct contact (Tidhar et al. 2007; Haapakoski et al. 2012).

We conducted our study at Konnevesi Research Station in Central Finland $\left(62^{\circ} 37^{\prime} \mathrm{N}, 26^{\circ} 20^{\prime} \mathrm{E}\right)$. In the laboratory, males and females were maintained in the same room. The adult voles used in the study were wild-caught individuals that 
were housed in the lab during the winter months preceding the study period. Winter colonies are formed from the last cohort of voles of the previous summer. Thus, their age at the time of the experiment is about 7 months. The winter population is housed on a short photoperiod (8L:16D) at around $17{ }^{\circ} \mathrm{C}$ throughout the winter and male voles' testes are abdominal and female vaginas are closed. Samples were taken from non-reproductive animals, to minimize contamination related to oestrus cycles or sexual maturity. All animals were individually marked with ear tags (\#1005-1L1, National Band \& Tag Company, Newport, KY, USA). Voles were kept individually in $42 \mathrm{~cm} \times 26 \mathrm{~cm} \times 15 \mathrm{~cm}$ transparent cages with wire mesh lids and supplied with ad libitum water and food. 7 days prior to sampling voles were placed into smaller $24 \times 18 \times 14 \mathrm{~cm}$ cages, equipped with the glass sampling container. The bedding materials in each cage consisted of wood shavings and hay.

Weasels were housed individually in $60 \mathrm{~cm} \times 160 \mathrm{~cm} \times 60 \mathrm{~cm}$ cages in an outdoor shelter. Each cage had a nest box and wood shavings and hay as bedding. Throughout the experiment (and during the two-week period before its initiation), weasels were exclusively fed dead bank voles.

\section{Treatments and VOC sampling}

One week before sampling, voles were changed to the small sampling cages containing their usual bedding, including a glass sampling container with a volume of $250 \mathrm{ml}$ covered with a dark cardboard sleeve to simulate a safe refuge. This served to minimize the stress to the vole as much as possible. The control (C) treatment was achieved by switching the glass container for a clean one. The lid to the glass container was closed as soon as the vole entered it voluntarily. Every lid was fashioned with an inlet and outlet and the inside of each lid was covered with a sheet of polytetrafluoroethylene to prevent reactions of the VOC with the lid. Once the lid was attached, the sampling of the air from the chamber to get the control sample was started. The handling $(\mathrm{H})$ treatment consisted of $3 \mathrm{~min}$ of simulated standard handling procedures by the same researcher for every sampling (sexing, checking ear tag, checking PIT tag etc.) after which the animals were immediately transferred to a sampling container. For the predator $(\mathrm{P})$ treatment, a vole in a live trap (Ugglan Special, Grahnab AB, Gnosjö, Sweden), was introduced into a weasel cage for $3 \mathrm{~min}$. Afterwards, the vole was directly transferred into the sampling container. Each vole was sampled for VOCs individually.

Containers were cleaned at $75{ }^{\circ} \mathrm{C}$ for 20 min with water before and between sampling bouts. Pressurized (Gardner Denver Thomas GmbH, Puchheim, Germany) and filtered, both through an air filter (Wilkerson model M03-C2-X00; Wilkerson Corp., Richland, MI, USA) and through active charcoal, inlet air was introduced into glass containers at a flow rate of $255-260 \mathrm{ml} \mathrm{min}^{-1}$. After $20 \mathrm{~min}$ of flushing air through the tubes and filters, but not the sampling containers, VOC emissions were collected for 20 min (length determined with pilot samples) into pre-conditioned cartridges filled with $200 \mathrm{mg}$ Tenax TA (60/80 mesh, Markes International, UK) positioned at the outlet of the glass container. Cartridges were connected via clean silicone tubes to a vacuum pump (Bühler Technologies $\mathrm{GmbH}$, Ratingen, Germany), which pulled air through the cartridges with a flow rate of $240 \mathrm{ml} \mathrm{min}^{-1}$. Inlet and outlet airflows were calibrated with a gas flow calibrator (mini Buck calibrator, Buck, USA).

After collection, cartridges were stored at $4{ }^{\circ} \mathrm{C}$ for a maximum of 3 weeks before analysis. Blanks (collected from empty glass containers) were also sampled with the same method to identify potential contaminants. The blanks were collected daily from the room where the VOC collection took place and from inside the weasel cages to exclude a potential contamination of weasel odour in our samples. Analysis of VOCs collected into the cartridges was performed by GC-MS (7890A GC and 5975C VL MSD; Agilent Technologies, USA) with samples thermally desorbed with an automated thermal desorption unit (TD-100; Markes International Ltd, UK). Samples were desorbed at $250{ }^{\circ} \mathrm{C}$ for $10 \mathrm{~min}$, and cryofocused at $-30{ }^{\circ} \mathrm{C}$ in splitless mode. The column used to separate molecules was an HP5-MS (60 $\mathrm{m} \times 0.25 \mathrm{~mm} \times 0.5 \mu \mathrm{m}$, Agilent, USA). The chromatographic program was set up as follows: $40^{\circ} \mathrm{C}$ at the start with a hold of $2 \mathrm{~min}$, a $3{ }^{\circ} \mathrm{C} \mathrm{min}-1$ temperature ramp until $210^{\circ} \mathrm{C}$, and then a $10{ }^{\circ} \mathrm{C} \mathrm{min}{ }^{-1}$ temperature ramp to $300{ }^{\circ} \mathrm{C}$. This last temperature was held for $5 \mathrm{~min}$ to clean the column. The carrier gas was helium. VOC identification was conducted via comparison with a series of analytical standards [see Saunier and Blande (2019)], comparison of mass spectra to the NIST and Wiley libraries and the calculation of Kovats indices (through the injection of alkanes $\mathrm{C}_{8}-\mathrm{C}_{20}$ ) with comparison to available literature (Adams 2007) (https://webbook.nist.gov/). The following analytical standards were used: 2-hexenal, 3-hexen-1-ol, benzaldehyde, 3-hexen-1-ol acetate, nonanal, benzyl nitrile, methyl salicylate, alpha-pinene, beta-pinene, beta-myrcene, alpha-phellandrene, 3-carene, limonene, eucalyptol, ocimene, linalyl acetate, caryophyllene, bisabolol. Once the identification was done, the quantification for each compound was realized based on calibration curves obtained with the injection of analytical standards used for identification. Then, we normalized the quantity obtained according to the inlet and outlet flows as well as the time of collection (see below).

We provide the experimental $\mathrm{m} / \mathrm{z}$ spectra of 2-ocatanone, 1-octanol, and unknown compound 7 (Appendix 1), along with the theoretical NIST spectra for 2-ocatanone and 1-octanol (Appendix 2) in the Supplemental Material. 
A total of 23 voles was used in this experiment, 13 for the $\mathrm{C}$ treatment and the same ten animals for both $\mathrm{H}$ and $\mathrm{P}$.

\section{Field experiment}

Field study was conducted using five 0.25 -ha outdoor enclosures close to the Konnevesi Research Station in Central Finland (Ylönen and Eccard 2004) during July and August. Eight voles (four of each sex) were released in five enclosures each. With two repetitions, this resulted in 80 voles total. The enclosures were emptied of other rodents by live trapping before each replication. One week after releasing the voles, three wooden boxes $(60 \times 40 \times 30 \mathrm{~cm})$, with lids, about $10 \mathrm{~m}$ apart from each other, were arranged in a triangle at the centre of each enclosure. Each box contained one odour cue, control $(\mathrm{C})$, predator odour (PO) or alarm pheromone (AP). The $1 \mathrm{dl}$ odour cues were obtained as described in Sievert et al. (2020), i.e. clean wood shaving, soiled bedding from weasel cages, and bedding from weasel exposed voles, respectively. Each box contained further a seed tray for determining foraging efficiency of voles under each treatment using the giving-up-density (GUD) method (Brown 1988) (explained in the next paragraph). The trays were lidless boxes $(19 \times 19 \times 6 \mathrm{~cm})$ containing $8 \mathrm{dl}$ of sand into which 20 unhusked sunflower seeds were mixed. The foraging patch was renewed each day, the sand was sieved and the remaining untouched seeds were counted to obtain the GUD.

Brown $(1988,1999)$ framed the harvest rate an animal makes at a given patch as a balance of the energetic gains and costs attributed to foraging effort, predation, and missed opportunity costs. The density of food remaining in a patch after the forager stops foraging is called a giving-up density (GUD) (Brown 1999) and reflects the point where the energy remaining in the patch is equal to or outweighed by the combined costs to the forager. The GUD, as a method, has been adapted to test a large variety of elements affecting the strategic decisions animals take (Bedoya-Perez et al. 2013) and has been widely applied as a measure for habitat use (Ylönen et al. 2002; Orrock et al. 2004; Bleicher et al. 2018). In predator-prey studies, a low GUD (more consumed) is interpreted as an indicator of low perceived predation risk, while a high GUD (less consumed) is an indicator of a high perceived predation pressure(Brown 1999; Bedoya-Perez et al. 2013; Bleicher 2017).

\section{Data analysis}

The Emission Rates of VOCs collected by dynamic headspace sampling (ER) were calculated with the following formula:
$\mathrm{ER}=\frac{X * A i}{t * A o}$

with ER expressed in $\mathrm{ng} * \mathrm{~h}^{-1} *$ vole $^{-1} . X$ is the compound quantity (ng), $A i$ and $A o$ are the inlet and outlet air flows (ml * $\left.\min ^{-1}\right)$, respectively, and $t$ is the sampling time in $\mathrm{h}$.

Statistical analyses were performed with the R software (R Core Team 2021). Partial Least Squares Discriminant Analysis (PLS-DA) was performed on ER for all treatments using the package 'vegan' (Oksanen et al. 2020) and 'RVAideMemoire' (Hervé 2021) with a cross-validation based on 50 submodels (fivefold outer loop and fourfold inner loop). Pairwise tests were performed based on PLSDA with 999 permutations to highlight the differences between treatments. The PLS-DA graphics were drawn with 'MetaboAnalystR' (Chong and Xia 2018; Chong et al. 2019). The Variables Importance for Projection (VIP) scores, obtained through PLS-DA, were used to select the compounds of interest (the ten compounds with the highest scores). Kruskal-Wallis tests followed by Nemenyi post hoc tests were done for these components of interest to compare the ER.

For the GUD measurements, generalized linear mixed models (GLMM) with a Poisson distribution were calculated, 'Ime4' (Bates et al. 2015). To achieve the best model fit, first the interaction was removed, then other factors, only leaving Treatment for the simplest model. Each treatment was compared to the $\mathrm{C}$ (control) treatment. The most fitting model was chosen based on AICc, package 'MuMIn' (Barton 2020). A model was considered the best if the difference in AICc from the next model was greater than 2.5. Appropriate random effects were chosen by AICc.

All plots were generated with 'ggplot2' (Wickham 2016) and 'MetaboAnalystR' (Chong and Xia 2018; Chong et al. 2019).

\section{Results}

\section{Emission rates}

To investigate differences at the compound level, PLS-DA was performed for the emission rates of the individual compounds emitted for each treatment (Fig. 1). A global permutation test of the PLS-DA showed significant differences (PLS-DA, 999 permutations, $P=0.001$ ), while a pairwise permutation test confirmed these (PLS-DA, 999 permutations, $P=0.001)$ for all three pairwise comparisons. An analysis of the ten compounds of interest revealed significantly higher ER in the $\mathrm{P}$ treatment compared to both $\mathrm{H}$ and C, analysed by a Kruskal-Wallis test (Table 1). None of the ten compounds was detected in the $\mathrm{C}$ samples, and five were detected in the $\mathrm{H}$ samples at a low rate (Fig. 2). An analysis 


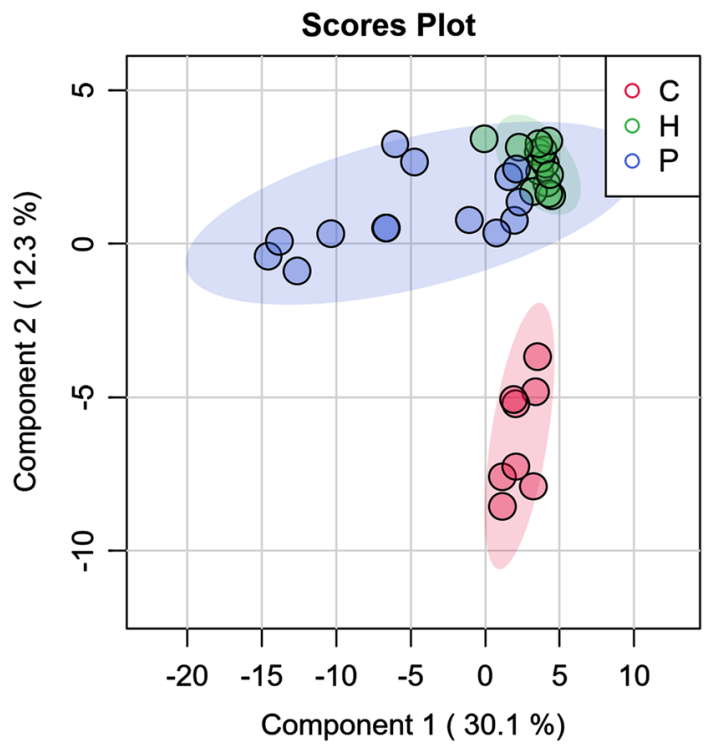

Fig. 1 Partial Least Squares-Discriminant Analysis (PLS-DA) based on emission rates according to treatment. Treatments: control (C), Handling $(\mathrm{H})$, and Predator $(\mathrm{P})$

focusing on sex differences for the ten compounds found no significant differences.

\section{Giving-up-densities}

The effects of predation risk cue and AP on the GUDs were similar during the first day of the experiment. Voles foraged on average 1.25 seeds less in the PO patch (GLMM, $\mathrm{d} f=6$, $P=0.0403$ ) compared to the $\mathrm{C}$ patch during the first day (Fig. 3). On the second day (Fig. 3), the voles foraged overall about $30.2 \%$ more (GLMM, d $f=6, P=0.004$ ) but significantly more, about $74.3 \%$ more in the AP patch (GLMM, $\mathrm{d} f=6, P<0.001)$.

\section{Discussion}

The first result in the volatile compound (VOC) analyses shows clearly that a disturbed or scared individual smells differently than an undisturbed control vole (Fig. 1). The grouping of the different treatments clearly shows no overlap of the VOCs of animals from the control group and animals from either the handling or weasel exposure group. This simple result verifies the idea that animals can use body odours for signalling and information exchange between conspecifics (Flood 1992; Inagaki et al. 2009; Wilson et al. 2018). The handling and predator-scared groups overlap. However, the range of handling compounds seems to be very narrow compared to the wider range of possible fear compounds.

Further, our study could identify and narrow down the list of possible VOCs, which could act as alarm pheromones in bank voles. We were able to identify ten compounds of interest, which all appear with higher emission rates in animals who previously encountered a weasel ( $P$ treatment). We also were able to show that in our field experiment, AP secretion lost their alarming function and efficiency after just one day in the field. It seems that after the volatile alarming compounds vanish, longer lasting social odours are left and, as shown in many studies before, social odours may signal safety (Kiyokawa 2015; Al Aïn et al. 2017) and they could attract voles for nonrisky foraging.

From our list of ten compounds of interest, most have been previously found in animals (see Appendix 3. for a list of references) with the exception of Car-3-en-2-one, which to our knowledge has not been found in other animals. Two of them have previously been associated with alarm pheromones or other alarm secretions. 2-Octanone

Table 1 Top 10 alarm pheromone components, sorted by VIP score

\begin{tabular}{|c|c|c|c|c|c|c|}
\hline Component & CAS & $\begin{array}{l}\text { Retention time } \\
\text { (minutes) }\end{array}$ & VIP score & $\begin{array}{l}\text { Difference } \mathrm{C}-\mathrm{H} \\
(P \text { value })\end{array}$ & $\begin{array}{l}\text { Difference } \mathrm{C}-\mathrm{P} \\
(P \text { value })\end{array}$ & $\begin{array}{l}\text { Difference } \\
\mathrm{H}-\mathrm{P}(P \\
\text { value })\end{array}$ \\
\hline 3-octen-2-one & $1669-44-9$ & 23.433 & 1.897 & 1 & 0.005 & $<0.001$ \\
\hline 3-methylbutanal & $590-86-3$ & 6.986 & 1.896 & 1 & 0.005 & $<0.001$ \\
\hline 2-amylfuran & $3777-69-3$ & 21.031 & 1.755 & 1 & 0.01 & 0.002 \\
\hline 2-octanone & $111-13-7$ & 20.957 & 1.755 & 1 & 0.01 & 0.002 \\
\hline camphene & $79-92-5$ & 18.898 & 1.753 & 1 & 0.01 & 0.002 \\
\hline 3-3-5-trimethylcyclohexanol & $116-02-9$ & 24.150 & 1.683 & 0.95 & 0.007 & 0.004 \\
\hline Unknown compound 7 & NA & 31.087 & 1.676 & 0.955 & 0.006 & 0.003 \\
\hline 1-octanol & $111-87-5$ & 25.016 & 1.674 & 0.95 & 0.007 & 0.004 \\
\hline Car-3-en-2-one & $107493-44-7$ & 32.243 & 1.649 & 0.861 & 0.003 & 0.004 \\
\hline Butyrolactone & $96-48-0$ & 16.972 & 1.624 & 0.924 & 0.009 & 0.007 \\
\hline
\end{tabular}

The CAS identifier together with the retention time is reported for each component. $P$ values for the Nemenyi post hoc test for each comparision are shown 

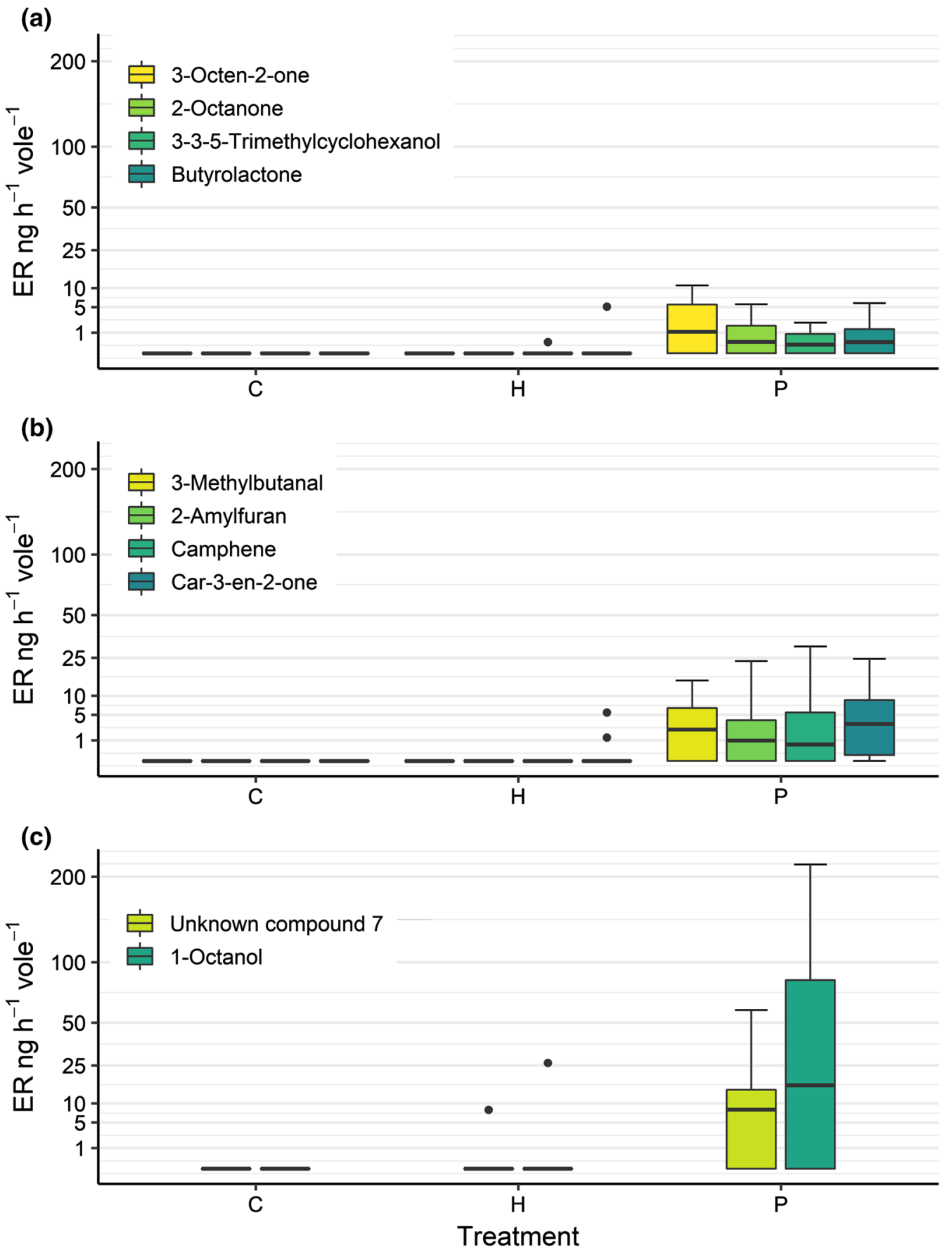

Fig. 2 Total emission rates (ng $* \mathrm{~h}^{-1} *$ vole $^{-1}$ ) for the compounds of interest, grouped by treatment. Treatments: control (C), Handling $(\mathrm{H})$, and Predator $(\mathrm{P})$. Components in panel $\mathbf{a}, \mathbf{b}$ and $\mathbf{c}$ are grouped by

has been found in the alarm secretions of several ant species (Crewe and Blum 1970a; Dumpert 1972; Brand et al. 1989) and lorises (Hagey et al. 2007). 1-Octanol has been found in the alarm secretions of several bee species (Johnson et al. 1985; Collins et al. 1989; Hunt et al. 2003) and stink bugs (Yamashita et al. 2016). 1-Octanol also showed the highest emission rate of all compounds of interest in maximum emission rates during the experiment for an easier visual comparison. All components show significant differences between $\mathrm{P}$ vs $\mathrm{C}$ and $\mathrm{P}$ vs $\mathrm{H}$, see Table 1 for details

our experiment (Fig. 2), followed by unknown compound 7. We provide the experimental $\mathrm{m} / \mathrm{z}$ spectra of 2 -ocatanone, 1-octanol, and unknown compound 7 , along with the theoretical NIST spectra for 2-ocatanone and 1-octanol in the Supplemental Material.

Evidence of interpreting heterospecific alarm cues is well established, however only in the aquatic environment 


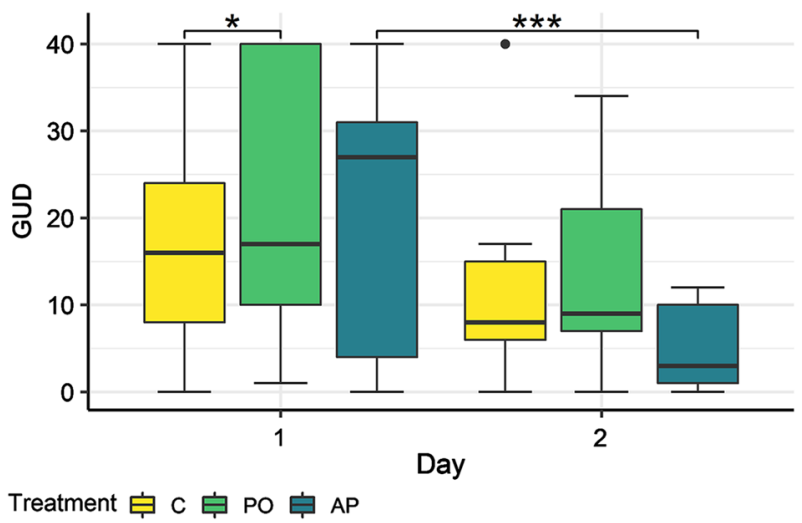

Fig. 3 Giving-up density by treatment. Treatments: control (C), predator odour $(\mathrm{PO})$, and alarm pheromone (AP). Asterisk $(*)$ indicates a significant difference from control at $P<0.05$. Three asterisks $(* * *)$ in this figure indicate a significant difference from the same treatment on the previous day at $P<0.001$

(Briones-Fourzán et al. 2008; Vogel et al. 2017; Magellan et al. 2019), with the exception of one termite species (Cristaldo et al. 2016). While there is strong evidence that phylogenetic closeness is a major factor (Hazlett and McLay 2005), there is evidence of cross-phyla communication (Kaliszewicz and Uchmański 2009). In terrestrial species, interspecies communication of alarm signals appears most commonly with alarm calls (Templeton and Greene 2007; Vitousek et al. 2007; Lea et al. 2008; Magrath et al. 2009). Within vertebrates, there are examples of the ability to interpret alarm calls correctly across taxonomic classes (Vitousek et al. 2007; Lea et al. 2008).

While our experiment does not provide the data to conclude whether there is a common structure in alarm chemicals, there is evidence from previous work permitting us to entertain the possibility. This would be a potential explanation for the occurrence of our identified compounds in, mostly, insects. In our study, we took only into account the major compounds to highlight potential alarm pheromone. However, we could have missed important signals by choosing this method. Indeed, it has been shown in plant-insect interactions, that minor compounds could have an important effect as chemical cues just like major compounds (Clavijo Mccormick et al. 2014). To go further, a similar experiment should be done focused on minor compounds.

A previous attempt to find a common features of olfactory communication (in terrestrial vertebrates) concluded that the range of compounds is widespread and bigger range of species is needed for proper conclusions (Apps et al. 2015). We share the assessment, as the studies on mammalian alarm pheromones are scarce. Unlike the work by Brechbühl et al. (2013), which found sulphur-containing compounds, our compounds of interest did not include any nitrogen- or sulphur-containing chemicals. This might be partially due to a completely different sampling method. While our method is non-invasive, the work by Brechbühl et al. (2013) included $\mathrm{CO}_{2}$ euthanasia to induce stress. Their results have been challenged by (Kiyokawa et al. 2013), pointing out that sampling from sacrificed animals results in collecting early decay volatiles. However, work on rats identified sulphur- or nitrogen-free chemicals as AP (Inagaki et al. 2014). Their work, with methods comparable to ours, identified 4-methylpentanal and hexanal as potential APs, which were not part of our compounds of interest.

While sampling from live animals allows for a greater risk of contaminations, it also allows for more ecologically relevant information. In our experiment, the animals were contained, but similar methods showed the possibility to sample from freely roaming individuals (Weiß et al. 2018). Our methods aimed for a non- or minimal-invasive approach, but also to apply a stimulus, i.e. predator exposure, that is similar to a stimulus in the wild. We believe that the methods in this experiment represent a good balance between a controlled and natural environment.

In our field experiment, no clear difference in foraging effort was observed in the AP GUD was observed on the first day, which is in line with our previous results (Sievert et al. 2019). However, a clear increase in foraging effort in AP patches after just one day, we suggest two factor for explaining this result. First, the AP is very short-lived and the remaining odour just signals the presence of conspecifics, or, secondly, the AP becomes rapidly so diluted that it requires a greater investigation effort (Parsons et al. 2018), which in turn leads to the discovery of food resources in the GUD patches and increased foraging. Either way, the information content concerning a predator presence or risk appears to be minimal at this point. Previous studies on bank vole AP argued that it is secreted in cases of immediate and acute risk (Sievert et al. 2019) and should it have an effective alarming function, it needs a rapid transfer to other conspecifics, group members or even kin. The short-lived character of AP in the field experiment supports this idea.

While weasels are the main factor of vole mortality (Norrdahl and Korpimäki 1995), previous work on voleweasel interactions has shown that, if presented with the opportunity, bank voles prefer to take arboreal escape routes while chased and weasels are unlikely to follow (Mäkeläinen et al. 2014). This, or other immediate survival enhancing responses, increase the chance for a successful escape and lays the fundament for evolution of adaptive signalling of conspecifics via AP.

To summarize, in this study, we adapted a new method to identify a group of chemicals likely to serve as alarm pheromone compounds in a common mammal species, the bank vole. Three of those, namely 1-octanol, 2-octanone, and unknown compound 7 , are likely to be the main actors. In the field experiment, we confirmed that the information 
carried in AP is short-lived, as we were expecting if AP functions to signal an acute and rapid event of very high risk. Our result expands the knowledge on predator-prey interactions and how predation risk can be communicated to unaware conspecifics.

Supplementary Information The online version contains supplementary material available at https://doi.org/10.1007/s00442-021-04977-w.

Acknowledgements We would like to thank Brigitte Weiß and Anja Widding for discussion and advice at an early planning stage. We would also like to thank the technical staff at the Konnevesi Research Station for building the necessary equipment.

Author contribution statement $\mathrm{TS}, \mathrm{MH}, \mathrm{JDB}, \mathrm{AS}$, and $\mathrm{HY}$ designed the study. TS, AS, OY and DH collected data. TS and AS performed the analysis. TS, MH, HY, AS and JDB were involved in writing the manuscript.

Funding Open access funding provided by University of Jyväskylä (JYU). The study was funded by an Academy of Finland grant awarded to HY (Project No. 288990).

Availability of data and material The R code is available from the figshare repository at https://doi.org/10.6084/m9.figshare.13148465 and the raw data is available from the figshare repository at https://doi.org/ $10.6084 / \mathrm{m} 9$.figshare. 13148351

Code availability The $\mathrm{R}$ code is available from the figshare repository at https://doi.org/10.6084/m9.figshare.13148465.

\section{Declarations}

Conflict of interest The authors have no conflict of interest or competing interests.

Ethics approval All experiments were conducted in accordance with institutional, European, and national guidelines. Experiments were conducted under permission for animal experimentation from the University of Jyväskylä No.ESAVI/6370/04.10.07/2014 granted by the Regional State Administrative Agency for Southern Finland (Etelä-Suomen aluehallintovirasto). Keeping weasels in captivity for experimental use was done under the permission KESELY/2022/2015 granted by the Centre for Economic Development, Transport and the Environment for Central Finland (Keski-Suomen ELY-keskus).

Consent to participate Not applicable.

Consent for publication Not applicable.

Open Access This article is licensed under a Creative Commons Attribution 4.0 International License, which permits use, sharing, adaptation, distribution and reproduction in any medium or format, as long as you give appropriate credit to the original author(s) and the source, provide a link to the Creative Commons licence, and indicate if changes were made. The images or other third party material in this article are included in the article's Creative Commons licence, unless indicated otherwise in a credit line to the material. If material is not included in the article's Creative Commons licence and your intended use is not permitted by statutory regulation or exceeds the permitted use, you will need to obtain permission directly from the copyright holder. To view a copy of this licence, visit http://creativecommons.org/licenses/by/4.0/.

\section{References}

Abrams PA (1986) Is predator-prey coevolution an arms race? Trends Ecol Evol 1:108-110. https://doi.org/10.1016/0169-5347(86) 90037-6

Abrams PA (2000) The evolution of predator-prey interactions: theory and evidence. Annu Rev Ecol Syst 31:79-105. https://doi.org/10. 1146/annurev.ecolsys.31.1.79

Adamo SA, McKee R (2017) Differential effects of predator cues versus activation of fight-or-flight behaviour on reproduction in the cricket Gryllus texensis. Anim Behav 134:1-8. https:// doi.org/10.1016/j.anbehav.2017.09.027

Adams RP (2007) Identification of essential oil components by gas chromatography/mass spectrometry, 4th edn. Allured Publishing Corporation, Carol Stream, Illinois, USA

Al Aïn S, Perry RE, Nuñez B et al (2017) Neurobehavioral assessment of maternal odor in developing rat pups: implications for social buffering. Soc Neurosci 12:32-49. https://doi.org/10. 1080/17470919.2016.1159605

Apps PJ (2013) Are mammal olfactory signals hiding right under our noses? Naturwissenschaften 100:487-506. https://doi.org/10. 1007/s00114-013-1054-1

Apps PJ, Weldon PJ, Kramer M (2015) Chemical signals in terrestrial vertebrates: search for design features. Nat Prod Rep 32:1131-1153. https://doi.org/10.1039/C5NP00029G

Barton K (2020) MuMIn: Multi-Model Inference. R package version 1.43.17. https://CRAN.R-project.org/package $=$ MuMIn

Bates D, Mächler M, Bolker B, Walker S (2015) Fitting linear mixedeffects models using lme4. J Stat Softw 67:1-48. https://doi. org/10.18637/jss.v067.i01

Beale MH, Birkett MA, Bruce TJA et al (2006) Aphid alarm pheromone produced by transgenic plants affects aphid and parasitoid behavior. Proc Natl Acad Sci 103:10509-10513. https:// doi.org/10.1073/pnas.0603998103

Bedoya-Perez MA, Carthey AJR, Mella VSA et al (2013) A practical guide to avoid giving up on giving-up densities. Behav Ecol Sociobiol 67:1541-1553. https://doi.org/10.1007/ s00265-013-1609-3

Bleicher SS (2017) The landscape of fear conceptual framework: definition and review of current applications and misuses. PeerJ 5:e3772. https://doi.org/10.7717/peerj.3772

Bleicher SS, Ylönen H, Käpylä T, Haapakoski M (2018) Olfactory cues and the value of information: voles interpret cues based on recent predator encounters. Behav Ecol Sociobiol 72:187199. https://doi.org/10.1007/s00265-018-2600-9

Blumstein DT, Daniel JC, Griffin AS, Evans CS (2000) Insular tammar wallabies (Macropus eugenii) respond to visual but not acoustic cues from predators. Behav Ecol 11:528-535. https:// doi.org/10.1093/beheco/11.5.528

Boissy A, Terlouw C, Le Neindre P (1998) Presence of cues from stressed conspecifics increases reactivity to aversive events in cattle: evidence for the existence of alarm substances in urine. Physiol Behav 63:489-495. https://doi.org/10.1016/S00319384(97)00466-6

Bowers WS, Nault LR, Webb RE, Dutky SR (1972) Aphid alarm pheromone: isolation, identification, synthesis. Science 177:1121-1122. https://doi.org/10.1126/science.177.4054. 1121

Brand JM, Page HM, Lindner WA, Markovetz AJ (1989) Are ant alarm-defense secretions only for alarm defense? Naturwissenschaften 76:277-277. https://doi.org/10.1007/BF00368641

Brechbühl J, Moine F, Klaey M et al (2013) Mouse alarm pheromone shares structural similarity with predator scents. Proc Natl Acad Sci 110:4762-4767. https://doi.org/10.1073/pnas. 1214249110 
Briones-Fourzán P, Ramírez-Zaldívar E, Lozano-Álvarez E (2008) Influence of conspecific and heterospecific aggregation cues and alarm odors on shelter choice by syntopic Spiny lobsters. Biol Bull 215:182-190. https://doi.org/10.2307/25470699

Brown JS (1988) Patch use as an indicator of habitat preference, predation risk, and competition. Behav Ecol Sociobiol 22:37-47. https://doi.org/10.1007/BF00395696

Brown JS (1999) Vigilance, patch use and habitat selection: foraging under predation risk. Evol Ecol Res 1:49-71

Chong J, Xia J (2018) MetaboAnalystR: an R package for flexible and reproducible analysis of metabolomics data. Bioinformatics 34:4313-4314. https://doi.org/10.1093/bioinformatics/bty528

Chong J, Yamamoto M, Xia J (2019) MetaboAnalystR 2.0: from raw spectra to biological insights. Metabolites 9:57. https://doi.org/ 10.3390/metabo9030057

Clavijo Mccormick A, Gershenzon J, Unsicker SB (2014) Little peaks with big effects: establishing the role of minor plant volatiles in plant-insect interactions. Plant Cell Environ 37:1836-1844. https://doi.org/10.1111/pce.12357

Clinchy M, Sheriff MJ, Zanette LY (2013) Predator-induced stress and the ecology of fear. Funct Ecol 27:56-65. https://doi.org/ 10.1111/1365-2435.12007

Collier K, Radford AN, Townsend SW, Manser MB (2017) Wild dwarf mongooses produce general alert and predator-specific alarm calls. Behav Ecol 28:1293-1301. https://doi.org/10. 1093/beheco/arx091

Collins AM, Rinderer TE, Daly HV et al (1989) Alarm pheromone production by two honeybee (Apis mellifera) types. J Chem Ecol 15:1747-1756. https://doi.org/10.1007/BF01012262

Crewe RM, Blum MS (1970a) Alarm pheromones in the genus Myrmica (Hymenoptera: Formicidae). Z Vgl Physiol 70:363-373. https://doi.org/10.1007/BF00298191

Crewe RM, Blum MS (1970b) Identification of the alarm pheromones of the ant Myrmica brevinodis. J Insect Physiol 16:141146. https://doi.org/10.1016/0022-1910(70)90121-6

Cristaldo PF, Rodrigues VB, Elliot SL et al (2016) Heterospecific detection of host alarm cues by an inquiline termite species (Blattodea: Isoptera: Termitidae). Anim Behav 120:43-49. https://doi.org/10.1016/j.anbehav.2016.07.025

Dehnhard M (2011) Mammal semiochemicals: understanding pheromones and signature mixtures for better zoo-animal husbandry and conservation. Int Zoo Yearbook 45:55-79. https://doi.org/ 10.1111/j.1748-1090.2010.00131.x

Dicke M, Sabelis MW (1988) Infochemical terminology: based on cost-benefit analysis rather than origin of compounds? Funct Ecol 2:131. https://doi.org/10.2307/2389687

Dumpert K (1972) Alarmstoffrezeptoren auf der Antenne von Lasius fuliginosus (Latr.) (Hymenoptera, Formicidae). Z Vgl Physiol 76:403-425. https://doi.org/10.1007/BF00337782

Eccard JA, Ylönen H (2006) Adaptive food choice of bank voles in a novel environment: choices enhance reproductive status in winter and spring. Ann Zool Fennici 43:2-8

Embar K, Kotler BP, Mukherjee S (2011) Risk management in optimal foragers: the effect of sightlines and predator type on patch use, time allocation, and vigilance in gerbils. Oikos 120:16571666. https://doi.org/10.1111/j.1600-0706.2011.19278.x

Evans CS (2006) Accessory chemosignaling mechanisms in primates. Am J Primatol 68:525-544. https://doi.org/10.1002/ ajp. 20250

Ferrero DM, Lemon JK, Fluegge D et al (2011) Detection and avoidance of a carnivore odor by prey. Proc Natl Acad Sci 108:1123511240. https://doi.org/10.1073/pnas.1103317108

Flood PF (1992) "Fragrance on the desert air": the semiochemistry of the muskox. In: Doty RL, Müller-Schwarze D (eds) Chemical signals in vertebrates 6. Springer, US, Boston, MA, pp 493-498
Gomes LAP, Salgado PMP, Barata EN, Mira APP (2013) Alarm scentmarking during predatory attempts in the Cabrera vole (Microtus cabrerae Thomas, 1906). Ecol Res 28:335-343. https://doi.org/ 10.1007/s11284-012-1023-8

Gutiérrez-García AG, Contreras CM, Mendoza-López MR et al (2007) Urine from stressed rats increases immobility in receptor rats forced to swim: role of 2-heptanone. Physiol Behav 91:166-172. https://doi.org/10.1016/j.physbeh.2007.02.006

Haapakoski M, Sundell J, Ylönen H (2012) Predation risk and food: opposite effects on overwintering survival and onset of breeding in a boreal rodent: predation risk, food and overwintering. J Anim Ecol 81:1183-1192. https://doi.org/10.1111/j.1365-2656. 2012.02005.x

Haapakoski M, Hardenbol AA, Matson KD (2018) Exposure to chemical cues from predator-exposed conspecifics increases reproduction in a wild rodent. Sci Rep 8:17214. https://doi. org/10.1038/s41598-018-35568-0

Hagey LR, Fry BG, Fitch-Snyder H (2007) Talking defensively, a dual use for the brachial gland exudate of slow and pygmy lorises. In: Gursky SL, Nekaris KAI (eds) Primate Anti-Predator Strategies. Developments in primatology: progress and prospects. Springer, US, Boston, MA, pp 253-272

Hansson L (1979) Condition and diet in relation to habitat in bank voles Clethrionomys glareolus: population or community approach? Oikos 33:55. https://doi.org/10.2307/3544511

Hazlett BA, McLay C (2005) Responses of the crab Heterozius rotundifronsto heterospecific chemical alarm cues: phylogeny vs. ecological overlap. J Chem Ecol 31:671-677. https://doi. org/10.1007/s10886-005-2054-1

Heath RR, Landolt PJ (1988) The isolation, identification and synthesis of the alarm pheromone of Vespula squamosa (Drury) (Hymenoptera: Vespidae) and associated behavior. Experientia 44:82-83. https://doi.org/10.1007/BF01960257

Hervé M (2021) RVAideMemoire: Testing and Plotting Procedures for Biostatistics. R package version 0.9-79. https://CRAN.Rproject.org/package $=$ RVAideMemoire

Howe N, Sheikh Y (1975) Anthopleurine: a sea anemone alarm pheromone. Science 189:386-388. https://doi.org/10.1126/ science. 238286

Hunt GJ, Wood KV, Guzmán-Novoa E et al (2003) Discovery of 3-methyl-2-buten-1-yl acetate, a new alarm component in the sting apparatus of Africanized honeybees. J Chem Ecol 29:453-463. https://doi.org/10.1023/A:1022694330868

Inagaki H, Nakamura K, Kiyokawa Y et al (2009) The volatility of an alarm pheromone in male rats. Physiol Behav 96:749-752. https://doi.org/10.1016/j.physbeh.2008.12.006

Inagaki H, Kiyokawa Y, Tamogami S et al (2014) Identification of a pheromone that increases anxiety in rats. Proc Natl Acad Sci 111:18751-18756. https://doi.org/10.1073/pnas.1414710112

Johnson LK, Haynes LW, Carlson MA et al (1985) Alarm substances of the stingless bee, Trigona silvestriana. J Chem Ecol 11:409416. https://doi.org/10.1007/BF00989552

Kaliszewicz A, Uchmański J (2009) A cross-phyla response to Daphnia chemical alarm substances by an aquatic oligochaete. Ecol Res 24:461-466. https://doi.org/10.1007/s11284-008-0522-0

Kats LB, Dill LM (1998) The scent of death: chemosensory assessment of predation risk by prey animals. Écoscience 5:361-394. https://doi.org/10.1080/11956860.1998.11682468

Kiyokawa Y (2015) Social odors: alarm pheromones and social buffering. Current topics in behavioural neuroscience. Springer Berlin Heidelberg, Berlin, Heidelberg, pp 47-65

Kiyokawa Y, Kikusui T, Takeuchi Y, Mori Y (2004) Alarm pheromones with different functions are released from different regions of the body surface of male rats. Chem Senses 29:3540. https://doi.org/10.1093/chemse/bjh004 
Kiyokawa Y, Kodama Y, Kubota T et al (2013) Alarm pheromone is detected by the vomeronasal organ in male rats. Chem Senses 38:661-668. https://doi.org/10.1093/chemse/bjt030

Koivula M, Koskela E, Mappes T, Oksanen TA (2003) Cost of reproduction in the wild: manipulation of reproductive effort in the bank vole. Ecology 84:398-405. https://doi.org/10.1890/00129658(2003)084[0398:CORITW]2.0.CO;2

Kuwahara Y, Leal WS, Nakano Y et al (1989) Phermone study on Astigmait Mites: XXIII. Identification of the alarm pheromone on the Acarid Mite, Tyrophagus neiswanderi and species specificities of alarm pheromones among four species of the same genus. Appl Entomol Zool 24:424-429. https://doi.org/10. 1303/aez.24.424

Lea AJ, Barrera JP, Tom LM, Blumstein DT (2008) Heterospecific eavesdropping in a nonsocial species. Behav Ecol 19:1041-1046. https://doi.org/10.1093/beheco/arn064

MacLean SA, Bonter DN (2013) The sound of danger: threat sensitivity to predator vocalizations, alarm calls, and novelty in gulls. PLoS ONE 8:1-7. https://doi.org/10.1371/journal.pone.0082384

Magellan K, Booth AJ, Weyl OLF (2019) Innate responses to conspecific and heterospecific alarm cues in the endangered eastern cape redfin Pseudobarbus afer. J Fish Biol. https://doi.org/10. $1111 / \mathrm{jfb} .14197$

Magrath RD, Pitcher BJ, Gardner JL (2009) Recognition of other species' aerial alarm calls: speaking the same language or learning another? Proc Royal Soc B Biol Sci 276:769-774. https://doi. org/10.1098/rspb.2008.1368

Mäkeläinen S, Trebatická L, Sundell J, Ylönen H (2014) Different escape tactics of two vole species affect the success of the hunting predator, the least weasel. Behav Ecol Sociobiol 68:31-40. https://doi.org/10.1007/s00265-013-1619-1

Mappes T, Ylönen H (1997) Reproductive effort of female bank voles in a risky environment. Evol Ecol 11:591-598. https://doi.org/ 10.1007/s10682-997-1514-1

Mappes T, Koskela E, Ylönen H (1995) Reproductive costs and litter size in the bank vole. Proc R Soc Lond B 261:19-24. https://doi. org/10.1098/rspb.1995.0111

Mathis A, Smith RJF (2008) Avoidance of areas marked with a chemical alarm substance by fathead minnows (Pimephales promelas) in a natural habitat. Can J Zool 70:1473-1476. https://doi.org/ 10.1139/z92-203

Meri T, Halonen M, Mappes T, Suhonen J (2008) Younger bank voles are more vulnerable to avian predation. Can J Zool 86:10741078. https://doi.org/10.1139/Z08-087

Mönkkönen M, Forsman JT, Kananoja T, Ylönen H (2009) Indirect cues of nest predation risk and avian reproductive decisions. Biol Lett 5:176-178. https://doi.org/10.1098/rsbl.2008.0631

Müller-Schwarze D (1983) Experimental modulation of behavior of free-ranging mammals by semiochemicals. In: Müller-Schwarze D, Silverstein RM (eds) Chemical signals in vertebrates 3 . Springer, US, Boston, MA, pp 235-244

Norrdahl K, Korpimäki E (1995) Mortality factors in a cyclic vole population. Proc Royal Soc B Biol Sci 261:49-53. https://doi. org/10.1098/rspb.1995.0116

Oksanen J, Blanchet FG, Friendly M, Kindt R, Legendre P, McGlinn D, Minchin PR, O'Hara RB, Simpson GL, Solymos P, Stevens MHH, Szoecs E, Wagner H (2020) vegan: Community Ecology Package. R package version 2.5-7. https://CRAN.R-project.org/ package $=$ vegan

Orrock JL, Danielson BJ, Brinkerhoff RJ (2004) Rodent foraging is affected by indirect, but not by direct, cues of predation risk. Behav Ecol 15:433-437. https://doi.org/10.1093/beheco/arh031

Ouattara K, Lemasson A, Zuberbuhler K (2009) Campbell's monkeys concatenate vocalizations into context-specific call sequences.
Proc Natl Acad Sci 106:22026-22031. https://doi.org/10.1073/ pnas.0908118106

Pankevich DE, Baum MJ, Cherry JA (2004) Olfactory sex discrimination persists, whereas the preference for urinary odorants from estrous females disappears in male mice after vomeronasal organ removal. J Neurosci 24:9451-9457. https://doi.org/10.1523/ JNEUROSCI.2376-04.2004

Parsons MH, Apfelbach R, Banks PB et al (2018) Biologically meaningful scents: a framework for understanding predator-prey research across disciplines. Biol Rev 93:98-114. https://doi.org/ 10.1111/brv.12334

Pérez-Gómez A, Bleymehl K, Stein B et al (2015) Innate predator odor aversion driven by parallel olfactory subsystems that converge in the ventromedial hypothalamus. Curr Biol 25:1340-1346. https:// doi.org/10.1016/j.cub.2015.03.026

R Core Team (2021) R: A language and environment for statistical computing. R Foundation for Statistical Computing, Vienna, Austria. https://www.R-project.org/

Randler C (2006) Disturbances by dog barking increase vigilance in coots Fulica atra. Eur J Wildl Res 52:265-270. https://doi.org/ 10.1007/s10344-006-0049-z

Roberts SA, Simpson DM, Armstrong SD et al (2010) Darcin: a male pheromone that stimulates female memory and sexual attraction to an individual male's odour. BMC Biol. https://doi.org/ 10.1186/1741-7007-8-75

Saunier A, Blande JD (2019) The effect of elevated ozone on floral chemistry of Brassicaceae species. Environ Pollut 255:113257. https://doi.org/10.1016/j.envpol.2019.113257

Sbarbati A, Osculati F (2006) Allelochemical communication in vertebrates: kairomones, allomones and synomones. Cells Tissues Organs 183:206-219. https://doi.org/10.1159/000096511

Setchell JM, Vaglio S, Abbott KM et al (2011) Odour signals major histocompatibility complex genotype in an Old World monkey. Proc Royal Soc B Biol Sci 278:274-280. https://doi.org/10.1098/ rspb.2010.0571

Sievert T, Haapakoski M, Palme R et al (2019) Secondhand horror: effects of direct and indirect predator cues on behavior and reproduction of the bank vole. Ecosphere 10:e02765. https://doi.org/ $10.1002 /$ ecs 2.2765

Sievert T, Kerkhoven A, Haapakoski M et al (2020) In utero behavioral imprinting to predation risk in pups of the bank vole. Behav Ecol Sociobiol 74:13. https://doi.org/10.1007/s00265-019-2791-8

Sih A (1994) Predation risk and the evolutionary ecology of reproductive behaviour. J Fish Biol 45:111-130. https://doi.org/10.1111/j. 1095-8649.1994.tb01087.x

Spehr M, Kelliher KR, Li XH et al (2006) Essential role of the main olfactory system in social recognition of major histocompatibility complex peptide ligands. J Neurosci 26:1961-1970. https://doi. org/10.1523/JNEUROSCI.4939-05.2006

Stenseth NC (1985) Geographic distribution of Clethrionomys species. Ann Zool Fenn 22:215-219

Stern K, McClintock MK (1998) Regulation of ovulation by human pheromones. Nature 392:177-179. https://doi.org/10.1038/32408

Sundell J, Ylönen H (2004) Behaviour and choice of refuge by voles under predation risk. Behav Ecol Sociobiol 56:263-269. https:// doi.org/10.1007/s00265-004-0777-6

Templeton CN, Greene E (2007) Nuthatches eavesdrop on variations in heterospecific chickadee mobbing alarm calls. Proc Natl Acad Sci 104:5479-5482. https://doi.org/10.1073/pnas.0605183104

Thornhill R, Gangestad SW (1999) The scent of symmetry: a human sex pheromone that signals fitness? Evol Hum Behav 20:175201. https://doi.org/10.1016/S1090-5138(99)00005-7

Tidhar W, Bonier F, Speakman JR (2007) Sex- and concentrationdependent effects of predator feces on seasonal regulation of 
body mass in the bank vole Clethrionomys glareolus. Horm Behav 52:436-444. https://doi.org/10.1016/j.yhbeh.2007.06.009

Townsend SW, Rasmussen M, Clutton-Brock T, Manser MB (2012) Flexible alarm calling in meerkats: the role of the social environment and predation urgency. Behav Ecol 23:1360-1364. https:// doi.org/10.1093/beheco/ars129

Van der Veen IT (2002) Seeing is believing: information about predators influences yellowhammer behavior. Behav Ecol Sociobiol 51:466-471. https://doi.org/10.1007/s00265-002-0464-4

Vieuille-Thomas C, Signoret JP (1992) Pheromonal transmission of an aversive experience in domestic pig. J Chem Ecol 18:1551-1557. https://doi.org/10.1007/BF00993228

Vitousek MN, Adelman JS, Gregory NC, Clair JJHS (2007) Heterospecific alarm call recognition in a non-vocal reptile. Biol Let 3:632-634. https://doi.org/10.1098/rsbl.2007.0443

Vogel C, Weber PD, Lang C, Baldisserotto B (2017) Conspecific and heterospecific alarm substances induce behavioral responses in juvenile catfish Rhamdia quelen. Neotrop Ichthyol. https://doi. org/10.1590/1982-0224-20160036

von Frisch K (1938) Zur Psychologie Des Fisch-Schwarmes. Naturwissenschaften 26:601-606. https://doi.org/10.1007/BF01590598

Wallace KJ, Rosen JB (2000) Predator odor as an unconditioned fear stimulus in rats: elicitation of freezing by trimethylthiazoline, a component of fox feces. Behav Neurosci 114:912-922. https:// doi.org/10.1037/0735-7044.114.5.912

Weiß BM, Marcillo A, Manser M et al (2018) A non-invasive method for sampling the body odour of mammals. Methods Ecol Evol 9:420-429. https://doi.org/10.1111/2041-210X.12888

Wickham H (2016) ggplot2: elegant graphics for data analysis. Springer-Verlag, New York, NY

Wilson AE, Sparks DL, Knott KK et al (2018) Behavioral, semiochemical and androgen responses by male giant pandas to the olfactory sexual receptivity cues of females. Theriogenology 114:330-337. https://doi.org/10.1016/j.theriogenology.2018.04.011

Wisenden BD, Vollbrecht KA, Brown JL (2004) Is there a fish alarm cue? Affirming evidence from a wild study. Anim Behav 67:5967. https://doi.org/10.1016/j.anbehav.2003.02.010

Yamashita K, Isayama S, Ozawa R et al (2016) A pecky rice-causing stink bug Leptocorisa chinensis escapes from volatiles emitted by excited conspecifics. J Ethol 34:1-7. https://doi.org/10.1007/ s10164-015-0437-5

Ylönen H (1989) Weasels Mustela Nivalis suppress reproduction in cyclic bank voles Clethrionomys Glareolus. Oikos 55:138. https://doi.org/10.2307/3565886

Ylönen H, Brown JS (2007) Fear and the foraging, breeding, and sociality of rodents. In: Wolff JO, Sherman PW (eds) Rodent societies: an ecological \& evolutionary perspective. University of Chicago Press, Chicago, IL, USA, p 610

Ylönen H, Eccard JA (2004) Does quality of winter food affect spring condition and breeding in female bank voles (Clethrionomys glareolus)? Ecoscience 11:1-5. https://doi.org/10.1080/11956 860.2004.11682803

Ylönen H, Ronkainen H (1994) Breeding suppression in the bank vole as antipredatory adaptation in a predictable environment. Evol Ecol 8:658-666. https://doi.org/10.1007/BF01237848

Ylönen H, Jacob J, Davies MJ, Singleton GR (2002) Predation risk and habitat selection of Australian house mice, Mus domesticus, during an incipient plague: desperate behaviour due to food depletion. Oikos 99:284-289. https://doi.org/10.1034/j.1600-0706. 2002.990208.x

Yoshida T, Jones LE, Ellner SP et al (2003) Rapid evolution drives ecological dynamics in a predator-prey system. Nature 424:303306. https://doi.org/10.1038/nature01767 